\title{
BIBLIOGRAPHIE
}

\section{Etudes sur la politique et les médias télévisuels}

ALBOUY, S., Marketing et communication politique, Paris, L'Harmattan, 1993.

ANTOINE F., Les radios et les télévisions de Belgique, Bruxelles, Kluwer, 2000.

BALANDIER, G., Le pouvoir sur scènes, Paris, Balland, 1992.

BONNAFOUS S., « La question de l'ethos et du genre en communication politique ", Actes du Premier colloque franco-mexicain de Sciences de la communication, Rennes : SFSIC, 2002.

— « «Femme politique»: une question de genre ? », in Réseaux, $\mathrm{n}^{\circ} 120$, Une communication sexuée?, 2003.

BOURDON, J., Haute fidélité. Pouvoir et télévision, 1935-1994, Paris, Seuil, 1994.

BRANTS, K., « Who's affraid of infotainment? », European Journal of Communication, 13(3): 315-335, 1998.

BRÉCHON, P., Le discours politique en France, Paris, La Documentation française, 1995.

BRETON, Ph., La parole manipulée, Paris, La Découverte Essais, 1997.

-, L'argumentation dans la communication, Paris, La Découverte, coll. "Repères", 1996.

BBURGELMAN, J.C., Omroep en politiek in België, Bruxelles, BRT, 1990.

CAYROL, R., La nouvelle communication politique, Paris, Larousse, 1986.

CHAMPAGNE, P., Faire l'opinion. Le nouveau jeu politique, Paris, Éd. du Seuil, 1990.

CHARAUDEAU, P.(dir.), La presse. Produit, production, réception, Paris Didier Érudition, 1988.

-, Le discours d'information médiatique. Paris:Nathan/INA, coll. "Médias Recherches", 1997.

—, Le discours politique. Les masques du pouvoir, Paris, Vuibert, 2005.

CHARAUDEAU, P., GHIGLIONE, R., La parole confisquée. Un genre télévisuel : le talk-show, Paris, Dunod, 1997.

CHARAUDEAU, P., LOCHARD, G. et alii, La télévision et la guerre. Déformation ou construction de la réalité ?, Bruxelles, De Boeck Université/INA, 2001.

CHARRON, J., La production de l'actualité politique, Montréal, Boréal, 1994.

Recherches en communication, $\mathrm{n}^{\circ} 24$ (2005). 
CORNER, J.,. " Visibility as truth and spectacle in TV documentary journalism ». In I. Bondebjerg (Ed.), Moving images, culture and the mind (pp. 143-153). Luton, University of Luton Press, 2000.

COTTERET, J.-M., Gouverner c'est paraître, Paris, P.U.F., coll. "Politique d'aujourd'hui', 2e éd., 1997.

COULOMB-GULLY, M., Radioscopie d'une campagne. La représentation politique au journal télévisé, Paris, Kimé, 1994.

- La démocratie mise en scènes. Télévision et élections, Paris, CNRS Editions, 2001.

C.U.R.A.P.P., La communication politique, Paris, P.U.F., 1991.

DARRAS E., «Les bienséances de l'échange politique », in Télévision et Politique, Politix $n^{\circ}$ 37, L'Harmattan, 1er trimestre 1997, pp. 9-24.

DARRAS, E., L'institution d'une tribune politique. Genèse et usages du magazine politique de télévision, Thèse de doctorat de science politique, Université de Paris II Panthéon-Assas, 1998, à paraître en 2006.

DELWIT, P., Composition, décomposition et recomposition du paysage politique en Belgique, Bruxelles, Labor, 2003.

DERVILLE G., Le pouvoir des médias. Mythes et réalités, Presses Universitaires de Grenoble, 1997.

de VIRIEU, F.-H., La médiacratie, Paris, Flammarion, 1990.

DOMENACH, J., La propagande politique, Paris, P.U.F., coll. “Que sais-je ?”, n 448 , 1979.

DOOVEY, J., Freakshow. Londres, Pluto Press, 2000.

DUMONT, J.-F., GREVISSE, B. et RINGLET, G., La presse écrite en Belgique, Diegem, Kluwer Editorial; $2^{\mathrm{e}}$ éd., 2000.

ELCHARDUS, M., La démocratie mise en scène, Bruxelles, Labor, 2004.

ESQUENAZI, J.-P., Le pouvoir d'un média : TF1 et son discours, Paris, L'Harmattan, coll. «Champs visuels», 1996.

—, Télévision et Démocratie, Paris, PUF, 1999.

GERSTLÉ, J., La communication politique, Paris, P.U.F., coll. “Que sais-je ?”, n 2652 , 1992.

—, La communication politique, Paris, Armand Colin, 2004.

GHIGLIONE, R. et BROMBERG, M., Discours politique et télévision. La vérité de l'heure, Paris, P.U.F., coll. «Psychologie sociale», 1998.

GOURÉVITCH, J.-P., La politique et ses images, Paris, Edilig, coll. «Médiathèque», 1986.

—, L'image en politique. De Luther à Internet et de l'affiche au clip, Paris, Hachette Littératures, 1998.

GROUPE SAINT-CLOUD, Présidentielle. Regards sur les discours télévisuels, Paris, Nathan/INA, coll. "Médias recherches", 1995.

HARTLEY, J.,. «The infotainment debate ». In G. Creeber (Ed.), The television genre book (pp. 118-120). Londres, BFI, 2002.

Hermès, $\mathrm{n}^{\circ} 1$, "Théorie politique et communication"; $\mathrm{n}^{\circ} 4$, «Le nouvel espace public» ; $\mathrm{n}^{\circ} 5-6$, "Individus et politique", $\mathrm{n}^{\circ}$ 17-18, "Communication et politique".

HIEL, J., “" Destination élections » : émission électorale ou télé-réalité ?”, Médiatiques, $\mathrm{n}^{\circ} 35$, automne 2004, pp. 50-52.

HUET, S. et LANGENIEUX-VILLARD, Ph., La communication politique, Paris, P.U.F., coll. «Politique aujourd'hui», 1982. 
IKER, L., Dépenses, limitations et procédures électorales. Guide pour les élections européennes, législatives, régionales et communautaires, Bruxelles, Idéal, 1998.

IKER, L., "Évolution des règles de financement et de contrôle des partis politiques", Courrier hebdomadaire, Bruxelles, CRISP, 1998, n 1607-1608.

JAMET, Cl. et JANNET, A.-M., La mise en scène de l'information; Les stratégies de l'information, Paris, L'Harmattan, 2 vol., coll. "Champs visuels", 1999.

JOST, Fr., La télévision au quotidien. Entre réalité et fiction, Bruxelles, De Boeck Université/INA, 2001.

KERBRAT-ORRECHIONI, C. et MOUILLAUD, M., Le discours politique, Lyon, Presses universitaires de Lyon, 1984.

LAMIZET, B., La médiation politique, Paris, L'Harmattan, 1998.

LANOTTE M., DUPONT Ch., JESPERS J.-J., L'univers au jour le jour, Bruxelles, Crédit communal/RTBF éditions, 1986.

LAPIERRE, J.-W., Le pouvoir politique et les langues : Babel et Leviathan, Paris, P.U.F., 1988.

Langages, Paris, Larousse, $\mathrm{n}^{\circ} 23$, "Le discours politique"; $\mathrm{n}^{\circ} 41$, "Typologie du discours politique" ; $n^{\circ} 62$, "Analyse du discours politique".

LANGE, Y., Médias et élections, Strasbourg, Éditions du Conseil de l'Europe, 1999.

LE BOHEC, J., Les rapports presse-politique. Mise au point d'une typologie "idéale", Paris, L'Harmattan, coll. "Logiques sociales", 1997.

—, L'implication des journalistes dans le phénomène Le Pen (vol. 1), Les interactions entre les journalistes et J.-M. Le Pen, (vol. 2), Paris, L'Harmattan, coll. "Logiques sociaes", 2004.

LE GRIGNOU, B. et NEVEU, E., « Intimités publiques. Les dynamiques de la politique à la télévision ", Revue française de science politique, vol 43, n 6 , décembre 1993, pp. 940-969.

LINDON, D., Le marketing politique, Paris, Dalloz, 1986.

LITS, M., "Personne privée, personnage public. Médiatisation et éthique", Communication, Québec, vol. 20, n² 2, février 2001, pp. 9-24.

- "La polémique médiatique comme lieu de confrontation politique contemporain", Recherches en communication, $\mathrm{n}^{\circ}$ 20, 2003, pp. 173-188.

LOCHARD, G., L'information télévisée, mutations et enjeux citoyens, Paris, Vuibert, 2005.

LOCHARD G. et SOULAGES J.-C., « La parole politique à la télévision. Du logos à l'ethos », Réseaux n 118.

MAAREK, Ph., Communication et marketing de l'homme politique, Paris, Litec, 1992 ; $2^{\mathrm{e}}$ éd. 2001.

Médiatiques. Récit et société, "Le discours politique", n²1, automne 2000, Louvainla-Neuve, UCL/COMU.

MEHL, D., La fenêtre et le miroir, Paris, Payot, 1992.

MESQUITA, M., "Le personnage journalistique. De la narratologie à la déontologie", Recherches en communication, $\mathrm{n}^{\circ} 11$, Louvain-la-Neuve, avril 1999, pp. 169-193.

Mots, $n^{\circ} 20$ et passim, Paris, Éditions de Sciences Po.

MOUCHON, J., La politique sous l'influence des médias, Paris, L'Harmattan, coll. "Communication", 1998.

MOUCHON, J. et MASSIT-FOLLÉA, Fr., Information et démocratie. Mutation du débat public, Paris, ENS Éditions, 1997.

NEL, N., Le débat télévisé, Paris, A. Colin, 1990. 
NEVEU E., « De l'art (et du coût) d'éviter la politique. La démocratie du talk-show version française », Réseaux $n^{\circ} 118$.

PAPATHANASSOPOULOS S., En libérant la Télévision, Kastaniotis, 1994.

PLEIOS G., Le discours de l'image. Idéologie et politique, Papazissis, 2001.

—, «La privatisation des médias et la formation du discours politique télévisé », in Demertzis N. (dir), La communication politique en Grèce, éditions Papazissi, 2002, pp. 235-280.

Pouvoirs, n 51, Paris, P.U.F., 1989.

Politix, “Télévision et politique", L'Harmattan, n 37, 1997.

PSILLA M., La communication politique en Grèce : le cas de la télévision, Thèse de Doctorat, Université Paris I, 1990.

RANGEON, F., La communication politique, Paris, P.U.F., 1991.

Réseaux, "La politique saisie par le divertissement", dossier coordonné par E. Neveu, $\mathrm{n}^{\circ} 118,2003$.

ROUQUETTE, S., Vie et mort des débats télévisés, 1958-2000, Bry-sur-Marne-Paris, INA-De Boeck, 2002.

SAUCEZ, Th., Le style réinvente la politique, Paris, Presses de la Renaisance, 2004.

SCHWARTZENBERG R.-G., L'Etat spectacle. Essai sur et contre le star system en politique, Paris, Flammarion, 1977.

SOUCHARD, M. et WAHNICH, S., La communication politique locale, Paris, P.U.F., coll. "Que sais-je ?", n 3039, 1995.

SOUCHARD, M., WAHNICH S. et alii, Le Pen. Les mots. Analyse d'un discours d'extrême droite, Paris, Le Monde Éditions, 1997. Réédité à La Découverte/Poche, coll. "Essais", 1998.

SOULAGES, J.-Cl., Les mises en scène visuelles de l'information, Paris, Nathan/INA, coll. "Médias - Recherches", 1999.

SOULEZ, G., "Ethos, énonciation, média. Sémiotique de l'ethos", Recherches en communication, $\mathrm{n}^{\circ} 18,2002$, pp. 175-198.

SAWANSON, D. L.. and MANCINI, P. (eds.), Politics, Media and Modern Democracy, Praeger, London, 1996.

THOVERON, G., La communication politique aujourd'hui, Bruxelles, De BoeckUniversité, 1991.

-, La marchandisation de la politique, Bruxelles, Labor, coll. "Quartier libre”, 2003.

TROGNON, A., Pragmatique du discours politique, Paris, A. Colin, 1994.

VOVOU I., La Démocratie à l'ère de la télévision. Les débats politiques à la télévision hellénique, Thèse de Doctorat, Université Paris III-Sorbonne Nouvelle, 2000.

—, «La construction symbolique du corps des femmes journalistes à la télévision grecque ", Questionner l'internationalisation, Actes du $14{ }^{\text {ème }}$ Congrès de la Société Française des Sciences de l'Information et de la Communication (juin 2004), pp. 163-170.

WITTE, E., Media en politiek, Bruxelles, VUBPress, 2002. 